\title{
O CORPO DIFERENTE: REPRESENTAÇÕES DAS RAÇAS HUMANAS NOS MANUAIS ESCOLARES DE ZOOLOGIA
}

\author{
Bento Filipe Barreiras Pinto Cavadas \\ Universidade Lusófona de Humanidades e Tecnologias, Portugal.
}

$\cos 8$

\section{Resumo}

Este trabalho visou comparar o modo como os autores dos manuais escolares de Zoologia, da segunda metade do século 19 e do início do século 20, realizaram a transposição didática dos estudos antropológicos sobre as raças humanas para essas obras. Constataram-se diferenças na tipologia e nos carateres antropológicos utilizados para descrever as raças humanas. Aferiu-se, ainda, a existência de afirmações que vincularam o determinismo biológico porque alguns autores valorizaram física, moral e intelectualmente a raça caucasiana em detrimento das outras raças. Palavras-chave: manuais escolares, raças humanas, zoologia.

\section{THE DIFFERENT BODY: REPRESENTATIONS OF THE HUMAN RACES IN ZOOLOGY TEXTBOOKS}

\section{Abstract}

The aim of this study is to compare how the authors of Zoology textbooks of the second half of 19th century and early 20th century made the didactic transposition of anthropological studies on the human races for these textbooks. The results show differences in the typology and anthropological characteristics used to describe the human races. It was also noticed the presence of statements related to the concept of biological determinism because the authors valued physic, morally and intellectually the Caucasian race instead other races. Key-words: textbooks, human races, zoology.

\section{EL CUERPO DIFERENTE: REPRESENTACIONES DE LAS RAZAS HUMANAS EN LOS MANUALES ESCOLARES DE ZOOLOGIA}

\section{Resumen}

Este estudio tuvo como objetivo comparar la forma en que los autores de los manuales escolares de Zoología de la segunda mitad del siglo 19 y principios del siglo 20 hizo la transposición didáctica de los estudios antropológicos sobre las razas humanas para estos manuales. Se encontraron diferencias en las características de la tipología y las características antropológicas 
utilizadas para describir las razas humanas. También se señaló que hay declaraciones que vinculaban el determinismo biológico debido a que algunos autores han valorizado física, moral e intelectualmente la raza caucásica sobre las otras razas.

Palabras-clave: manuales escolares, razas humanas, zoologia.

Résume

\section{LE DIFFERENT CORPS: REPRÉSENTATIONS DES RACES HUMAINES DANS LES MANUELS SCOLAIRES DE ZOOLOGIE}

Ce travail visait à comparer comment les auteurs des manuels scolaires de zoologie de la seconde moitié du $19 \mathrm{e}$ siècle et au début du $20 \mathrm{e}$ siècle mené la transposition didactique des études anthropologiques sur les races humaines pour ces manuels. Ont des différences dans la typologie et les caractères anthropologiques utilisés pour décrire des races humaines. Aussi a rassemblées l'existence de déclarations qui ont lié le déterminisme biologique parce que certains auteurs valorisé physique, moral et intellectuellement la race blanche au détriment des autres races. Mots-clé: manuels scolaires, les races humaines, zoologie. 


\section{Introdução}

pesar das iniciativas de várias agências governamentais e não-
governamentais para diminuir os conflitos raciais, estes continuaram a
intensificar-se no século 21. $\mathrm{Na}$ sua origem estão preconceitos raciais resultantes de distintas caraterísticas morfológicas corporais, mas também de diferenças étnicas, culturais e religiosas. Sem dúvida que o corpo diferente contribuiu para a classificação dos seres humanos em raças distintas, contudo, mesmo na atualidade, o conceito de raça humana continua a ser polissémico, é sujeito a ambiguidades e dificilmente gera consenso (Gould, 2004).

Os estudos raciais intensificaram-se no século 19, época das grandes investigações antropológicas. Portugal também fomentou alguns estudos antropológicos nas colónias e no território nacional. Destacaram-se, no final do século 19 e no início do século 20, etnógrafos como Consiglieri Pedroso, Adolfo Coelho, Teófilo Braga, Rocha Peixoto e José Leite de Vasconcellos (Leal, 2006).

O contacto dos europeus com povos estranhos levou à multiplicação de estudos sobre os seus carateres antropológicos, não apenas do corpo físico, mas também dos aspetos culturais. Nessa altura, a tese do determinismo biológico era comum na sociedade, conceito que Gould (2004) definiu como "a noção de que as pessoas das classes mais baixas são construídas com um material intrinsecamente inferior" (p. 69).

A esse respeito, Martins (1881), autor do livro As raças humanas e a civilização primitiva, referiu explicitamente que as "condições extremas de inferioridade constitucional física [...] impedem o desenvolvimento da civilização" (p. XL). Essas qualidades inferiores poderiam manifestar-se em carateres antropológicos desfavorecidos, como cérebros mais pequenos e menos inteligentes. Em consequência, a "hierarquia das raças naturais dos homens" (Martins, 1881, p. XL) era inevitável, tornando-se numa crença social comum nos séculos 18 e 19 (Gould, 2004). Essas conceções sustentaram afirmações semelhantes às que Martins (1881) emitiu acerca dos pigmeus dokkos: "domesticados, tornam-se escravos submissos e excelentes" (p. 4), validando, consequentemente, o esclavagismo.

Contudo, o modo como os conhecimentos científicos antropológicos vazaram para os manuais escolares de Ciências Naturais, nomeadamente de Zoologia, foi parcamente analisado. Com o objectivo de preencher essa lacuna, o presente estudo visou dar um contributo para o esclarecimento da forma como os autores dos manuais interpretaram a classificação antropológica das raças humanas e a transpuseram para esses instrumentos pedagógicos. Pretende-se responder ao seguinte problema: como foram apresentadas as raças humanas nos manuais escolares de Zoologia publicados na segunda metade do século 19 e no início do século 20? Para lhe dar resposta, estabeleceram-se os seguintes objetivos:

a) identificar os programas que prescreveram o estudo das raças humanas no período considerado e os manuais de Zoologia que abordaram essa temática em consonância com as determinações programáticas;

b) comparar a transposição didática dos tipos de raças humanas e respetivos carateres antropológicos nos manuais de Zoologia publicados em consonância com esses programas; 
c) analisar a vinculação de ideias relacionadas com o determinismo biológico.

\section{Revisão teórica}

No espaço lusófono, uma revisão da literatura sobre o racismo em livros didáticos brasileiros realizada por Rosemberg, Bazilli e Silva (2003) permitiu concluir que essa produção foi relativamente frágil, teórica e metodologicamente, fragmentada e inconstante, sendo poucos os autores ou grupos de pesquisa que trabalham sobre o tema por um período de tempo relativamente longo. Um dos estudos mais aprofundados sobre essa temática foi realizado por Stelling (2007), em manuais de Biologia do ensino médio, maioritariamente publicados entre 2004 e 2005. Numa abordagem à extensão, profundidade e modo de apresentação e desenvolvimento das conceções de raças humanas e raças biológicas, concluiu que o corpus de análise mostrou-se muito heterogêneo.

Enquanto alguns livros apresentam textos não-verbais (fotos, etc.) que parecem evidenciar grupos raciais humanos, outros pareceram evitar o termo raça ou explicitamente negaram a existência de raças humanas. Porém, e contraditoriamente, também utilizaram no mesmo texto o conceito cultural de grupos étnicos, como sinónimo de grupos fenotipicamente distintos. No que diz respeito a discursos sobre aspetos históricos e políticos sobre as raças humanas, Stelling (2007) aferiu que alguns manuais os incorporaram, enquanto outros não expuseram tensões sociais como o racismo, nem mencionaram aspetos históricos como o uso indevido do darwinismo social, a suposta desigualdade entre raças e o eugenismo.

Quanto aos manuais de Ciências Naturais portugueses, fizemos um estudo sucinto sobre as representações de estereótipos de diversas ordens, incluindo os raciais, em obras publicadas entre 1836 e 2005 (Cavadas, 2008). Esse estudo abreviado fez emergir, por um lado, a quase ausência de investigações sobre as representações raciais em manuais, nomeadamente em obras destinadas ao ensino das Ciências Naturais, e, por outro lado, a enorme riqueza que os manuais do passado aportam para esse campo de investigação.

Essa insuficiência de investigação é preocupante porque a presença de estereótipos raciais nos manuais não é uma questão menor dado que, como alertou Choppin (1992), é reconhecido o seu poder como ferramenta de vinculação ideológica, cultural e de valores para as gerações mais jovens. Sendo um produto cultural, o manual transmite através do conteúdo, e sem que os seus leitores tenham consciência disso, a cultura e a ideologia das classes dominantes, com o objetivo, implícito ou explícito, de uniformizar culturalmente uma sociedade. Quando o organizador de um manual escolhe determinado texto de um autor, rejeita os restantes em favor daquele que lhe parece mais adequado para transmitir a mensagem que visa passar aos destinatários do manual. Portanto, nesse instrumento pedagógico, o conhecimento que não merece o estatuto escrito é negligenciado.

Os manuais, ao organizarem e apresentarem aquilo que Morgado (2004) designou "cultura selecionada" (p. 27), contribuem para transmitir e legitimar o conhecimento que se considera útil que os alunos aprendam, desempenhando um papel crucial no 
desenvolvimento pessoal e social de cada indivíduo e na difusão da cultura dominante em detrimento de outras conceções ideológicas ${ }^{1}$.

Nesse contexto, os estereótipos de raça, religião, género, cultura ou condição social vinculados pelos manuais são suscetíveis de provocar conflitos entre diferentes raças e classes sociais, pelo que deve haver iniciativas que conduzam à sua supressão. Na verdade, atualmente, os manuais escolares possuem uma grande preocupação quanto à não transposição de preconceitos raciais:

em todos os manuais, independentemente do nível ou disciplina a que se dirigem, são analisados os preconceitos que, de maneira intencional ou funcional, explícita ou implícita, possam ser vetores. (Choppin, 1992, p. 204)

De facto, existe uma consciência internacional, por parte de organizações como a Unesco, para serem expurgados dos manuais estereótipos da mais variada ordem em detrimento de valores universais como a paz, os direitos humanos, a igualdade entre os sexos e o respeito pelo ambiente e minorias étnicas. Em consonância com essas orientações, foram realizadas algumas investigações sobre estereótipos de diversa ordem nos manuais portugueses, como os religiosos (Mucznik, 2007) e, principalmente, os de género (Martelo, 1999; Pinto, 1999; Rocha, 1999; Correia e Ramos, 2002; Pereira, 2003; Nunes, 2004; Caetano, 2005), todavia, os preconceitos raciais foram uma temática pouco focada em investigações análogas.

Sendo assim, a análise das expressões desses valores em manuais do presente é essencial, mas o seu estudo em manuais do passado também é importante, pois poderá conduzir a uma melhor compreensão dos manuais do presente. Por outro lado, a caraterização dos preconceitos raciais associados à ideia do determinismo biológico vinculados nos manuais do passado, poderá contribuir para a eliminação dos preconceitos raciais que eventualmente subsistam nos manuais do presente, ao consciencializar os respetivos autores da sua existência.

\section{Aspetos metodológicos}

Com o intuito de elucidar a questão-problema e alcançar os objetivos propostos, este estudo, de caráter qualitativo, centrou-se no conceito de transposição didática (Chevallard, 1991), na medida em que se procurou mostrar como os autores transformaram os conhecimentos científicos, ou seja, o "savoir savant" (p. 15), e as linhas programáticas, isto é, o "savoir à enseigner" (p. 15), sobre as raças humanas, em discurso textual nos manuais escolares. Após os programas estarem consolidados, inicia-se o processo que Chevallard (1991) designou por transposição didática interna: "lorsque les programmes sont fabriqués, signés, et prennent force de loi, un autre travail commence: celui de la transposition didactique interne" (p. 37).

Neste estudo, o discurso textual dos manuais escolares é entendido como um dos possíveis mediadores nesse processo de transposição didática interna entre o programa e o saber que será efetivamente transmitido aos alunos, ou seja, o "savoir enseigné" (p. 15),

\footnotetext{
${ }^{1}$ A esse respeito veja-se o conflito entre os criacionistas e os evolucionistas quanto ao modo como as teorias da origem das espécies devem ser apresentadas nos manuais (Scott, 2009).
} 
pelos professores no interior do espaço escolar. Para cumprir os objetivos propostos, esta investigação dividiu-se em três fases:

1. ${ }^{\text {a }}$ fase: esta etapa, heurística, consistiu na recolha dos programas escolares de Zoologia. Seguiu-se um momento hermenêutico, no qual foram analisados para se identificar se prescreveram, ou não, o estudo das raças humanas. O segundo momento heurístico visou a recolha dos manuais escolares de Zoologia do ensino liceal a analisar, tendo em conta os programas escolares anteriores. Essa pesquisa desaguou na constituição de um corpus de estudo (figura 1) restringido às primeiras edições dos manuais correspondentes às obras mais representativas da segunda metade do século 19 e do início do século 20 (Cavadas, 2008).

\section{Quadro 1}

Corpus de manuais escolares analisados.

\begin{tabular}{|c|c|c|c|c|c|}
\hline Ano & Título & Autor & $\begin{array}{c}\text { Anos } \\
\text { escolares }\end{array}$ & $\begin{array}{c}\text { Local de edição e } \\
\text { editora }\end{array}$ & $\begin{array}{l}\text { N. de } \\
\text { páginas }\end{array}$ \\
\hline 1859 & $\begin{array}{l}\text { Lições de zoologia } \\
\text { Elementar. 1. }{ }^{a} \text { parte }\end{array}$ & Silva Júnior & & $\begin{array}{l}\text { Lisboa: Typographia de } \\
\text { Castro \& Irmão. }\end{array}$ & 157 \\
\hline 1890 & $\begin{array}{l}\text { Elementos de } \\
\text { zoologia }\end{array}$ & $\begin{array}{l}\text { Maximiano } \\
\text { Lemos }\end{array}$ & $\begin{array}{l}4 .^{\circ} \text { e } 5 .^{\circ} \\
\text { anos. }\end{array}$ & $\begin{array}{l}\text { Porto: Lemos \& C. }{ }^{a} \text { - } \\
\text { Editores. }\end{array}$ & 277 \\
\hline 1906 & $\begin{array}{l}\text { Lições de zoologia. } \\
\text { V. } 2\end{array}$ & $\begin{array}{l}\text { Bernardo } \\
\text { Aires }\end{array}$ & $\begin{array}{l}4 .^{a} \text { e } 5 .^{a} \\
\text { classes }\end{array}$ & $\begin{array}{l}\text { Braga: Livraria Escolar } \\
\text { - Cruz e C. }\end{array}$ & 184 \\
\hline
\end{tabular}

2. ${ }^{a}$ fase: destinou-se à conceção da grelha de análise dos tipos de raças e dos respetivos carateres antropológicos presentes nos manuais escolares. Essa grelha, construída a posteriori, estruturou-se em torno de categorias de codificação (Bogdan e Biklen, 1994) antropológicas que resultaram da reunião de carateres comuns descritos pelos autores dos manuais: 1. Boca, dentes e lábios; 2. Cabelo, barba e pêlos; 3. Crânio, face e fronte; 4. Maxilas e mento; 5. Nariz; 6. Olhos; 7. Pele; 8. Proporções corporais.

3. ${ }^{a}$ fase: consistiu no estudo de cada um dos manuais com o intuito de analisar a transposição didática (Chevallard, 1991) dos conhecimentos antropológicos das raças humanas para essas obras, nomeadamente quanto: ao tipo de raças descrito; aos carateres antropológicos apresentados; à vinculação de ideias relacionadas com o determinismo biológico.

\section{Contextualização da temática nos programas e manuais de Zoologia}

O quadro seguinte resume as orientações programáticas de Zoologia para o ensino das raças humanas durante a segunda metade do século 19 e o início do século 20 (quadro 2). 
Quadro 2

Orientações programáticas para o estudo das raças humanas.

\begin{tabular}{|l|l|}
\hline Programa & Tópicos programáticos de Zoologia \\
\hline 1856 & $\begin{array}{l}\text { "Distribuição geográfica das raças humanas: revoluções operadas pelo } \\
\text { consórcio das raças". }\end{array}$ \\
\hline 1872 & $\begin{array}{l}\text { "Espécie humana. Carateres do homem: superioridade sobre os outros } \\
\text { animais. Idades. Noções sobre as principais raças humanas". }\end{array}$ \\
\hline 1880,1886, & $\begin{array}{l}\text { (Não contemplaram explicitamente uma rubrica para o estudo das raças } \\
\text { humanas.) }\end{array}$ \\
\hline 1888 e 1889 & $\begin{array}{l}\text { "Homem. Principais diferenças anatómicas entre o homem e os símios } \\
\text { superiores. Lugar do homem na natureza. Raças humanas." }\end{array}$ \\
\hline 1905 & "Raças humanas, seus principais carateres." \\
\hline 1919 & (Não foi contemplado o estudo das raças humanas.) \\
\hline
\end{tabular}

Um dos primeiros programas escolares de História Natural, Botânica e Mineralogia foi publicado em 1856 (Cavadas, 2008; Beato, 2012) e adotado no liceu de Coimbra (Beato, 2012). Após a sua publicação, e tendo como ponto de partida essa listagem de conteúdos científicos concretos e delimitados, começaram a ser redigidos os primeiros manuais, propriamente ditos, para o ensino da Zoologia. O primeiro manual a ser elaborado na sequência da publicação desse programa foi o livro Lições de zoologia elementar, redigido por Júnior e dividido em duas partes: a primeira parte foi publicada em 1859 e a segunda parte em 1860 (Cavadas, 2008).

Para este estudo interessa a primeira parte porque aborda a tipologia das raças humanas. É aí que Júnior (1859) deu cumprimento ao tópico programático "Distribuição geográfica das raças humanas: revoluções operadas pelo consórcio das raças" ${ }^{2}$, abordando as diferentes raças em que se divide o ser humano, que considerou ser "o primeiro, o mais nobre e majestoso ser da criação" (p. 152) e o que ocupa o lugar mais relevante na classificação zoológica.

Dezasseis anos mais tarde foi publicado o programa de História Natural de 1872 . O estudo das raças humanas foi incluído na quinta parte desse programa, numa secção designada Zoologia descritiva. Iniciava-se com a distinção entre classificação natural e artificial e prolongava-se pela classificação dos grandes grupos de animais, após a qual se seguem as temáticas "Espécie humana. Carateres do homem: superioridade sobre os outros animais. Idades. Noções sobre as principais raças humanas"3. Nesse item programático destaca-se o seu forte carácter antropocêntrico, pois prescrevia o estudo da espécie humana dando relevo à sua preponderância sobre os restantes organismos, em linha com as ideias vinculadas por Júnior (1859). Identificou-se apenas um manual redigido em conformidade com esse programa, contudo, como é manuscrito e está em mau estado de conservação, a sua legibilidade é muito reduzida, pelo que não foi analisado.

\footnotetext{
${ }^{2}$ PORTUGAL. Edital (s.d.). Diário do Governo n. 122, de 26 de maio de 1856, p. 702.

${ }^{3}$ PORTUGAL. Portaria de 5 de outubro de 1872. Diário do Governo, n. 231, de 12 de outubro de 1872, p. 1550.
} 
Na década seguinte, os programas de História Natural de $1880^{4}, 1886^{5}, 1888^{6}$ e $1889^{7}$ não consignaram explicitamente uma rubrica específica para o estudo das raças humanas na disciplina de Zoologia. Contudo, e usando como exemplo o programa de 1889, durante a exposição dos primatas na rubrica programática intitulada "Divisão dos vertebrados em classes. Divisão dos mamíferos em ordens. Descrição de um tipo de cada uma das principais ordens", foi abordada a temática das raças humanas no manual Elementos de zoologia para os $4 .^{\circ}$ e $5 .^{\circ}$ anos dos liceus, elaborado por Lemos (1890).

Nessa rubrica, o autor, na apresentação dos organismos que integram a Ordem dos Primatas, dividiu-os em simianos e hominianos. Considerou que os hominianos são representados por um único género, o Homo, que possui um forte desenvolvimento da cavidade craniana, correlativo com a profundidade e multiplicação das circunvoluções cerebrais. Afirmou que "d'estas disposições resulta uma inteligência superior à de todos os seres e que se manifesta pela linguagem articulada" (p. 265) e, após essas ilações, descreveu as raças humanas.

A citação anterior afirmação reflete as ideias que Gould (2004) considerou pertencerem a uma "teoria que apresentava a inteligência como uma entidade unitária, mensurável e geneticamente determinada" (p. 21). Não surpreende que a relação da inteligência com a forma e medidas do crânio tenha dado origem a inúmeros estudos e discussões, devido à sua controvérsia (Prats, 1988). Um dos seus mais acérrimos defensores foi Samuel Morton, antropólogo americano cujo trabalho no século 19 defendeu a hipótese de que uma hierarquização das raças poderia ser estabelecida objetivamente através das caraterísticas físicas do cérebro, especialmente através do seu tamanho médio (Gould, 2004). Essas ideias também foram espelhadas nos manuais analisados.

O estudo das raças humanas regressou no programa de Ciências Físicas e Naturais de 1895. O legislador voltou a prescrevê-lo na $7 .^{\text {a }}$ classe de Zoologia, na temática "Homem. Principais diferenças anatómicas entre o homem e os símios superiores. Lugar do homem na natureza. Raças humanas." " Todavia, apesar dos esforços empreendidos, não se conseguiu localizar nenhum manual de Zoologia para essa classe, mas apenas para as três primeiras classes liceais (Cavadas, 2008).

O programa seguinte, publicado em 1905, voltou a consignar esse estudo, mas desta vez isoladamente, na temática "Raças humanas, seus principais carateres" ${ }^{\text {, }}$, na $5 .^{\text {a }}$ classe de Zoologia. Aires, lente catedrático de Zoologia e Diretor do Museu Zoológico da Universidade de Coimbra, em conformidade com esse programa redigiu manuais intitulados Lições de zoologia, dividindo-os em três volumes. No capítulo 20 do volume 1 abordou a classificação dos mamíferos, iniciando-a pelo estudo de alguns carateres da

\footnotetext{
${ }^{4}$ PORTUGAL. Portaria (s.d.). Diário do Governo n. 241, de 21 de outubro de 1880, p. 2754.

${ }^{5}$ PORTUGAL. Portaria de 19 de novembro de 1886. Diário do Governo, n. 267, de 23 de novembro de 1886, p. 3392-3393.

${ }^{6}$ PORTUGAL. Portaria de 20 de outubro de 1888. Diário do Governo, n. 252, de 3 de novembro de 1888, p. 2438-2439.

${ }^{7}$ PORTUGAL. Portaria de 10 de outubro de 1889. Diário do Governo, n. 245, de 29 de outubro de 1889, p. 2471-2472.

8 PORTUGAL. Decreto de 14 de setembro de 1895. Diário do Governo, n. 208, de 16 de setembro de 1895 , p. 2519.

9 PORTUGAL. Decreto n. 3, de 3 de novembro de 1905. Diário do Governo, n. 250, de 4 de novembro de 1905, p. 3871.
} 
Ordem dos Primatas que incluía o ser humano e os macacos. Baseando-se no livro de Broca intitulado Mémoires d'anthropologie, referiu que a comparação dos órgãos do homem com os dos macacos revelava que ele "sob o ponto de vista estritamente zoológico" (Aires, 1906a, p. 235), difere menos dos antropoides do que estes dos macacos inferiores.

A sua perspetiva era que, apesar de "parecer estranho reunir o homem e os macacos na mesma ordem" (p. 235), ambos compartilhavam características como serem mamíferos com duas mãos, dois pés e duas mamas peitorais, e a atitude vertical do homem quanto à locomoção não se poder diferenciar da atitude oblíqua dos macacos, que só por exceção assentam no solo a palma das mãos. Curiosamente, acerca desse assunto, num estudo sobre racismo e o conceito de raça, numa amostra de manuais de Ciências Naturais e de Geografia publicados na Argentina entre 1870 e 1980 (Gvirtz, Valerani e Cornejo, 2005), foram tecidas considerações diferentes. A título de exemplo, veja-se as considerações de $\mathrm{H}$. Bruno, autor de um manual de Ciências Físicas e Naturais datado de 1940:

As características que distinguem o homem do animal são, acima de tudo, carateres morais e intelectuais que lhe atribuem uma superioridade imensa sobre todos os seres organizados. Do ponto de vista físico distingue-se principalmente pela abertura do ângulo facial, forma da mão, postura vertical e nudez da sua pele. (apud Gvirtz, Valerani e Cornejo, 2005, p. 476; sublinhados do autor)

Para H. Bruno, os seres humanos são organismos especiais no mundo natural, classificação que resulta quer das suas qualidades morais e intelectuais, quer de carateres como a postura bípede. Numa linha de pensamento distinta, Aires (1906a) afirmou que carateres como a postura bípede não são suficientes para classificar o ser humano num táxon apartado dos Primatas, cujos restantes organismos considerou serem "bípedes imperfeitos" (p. 235). Contudo, apesar de não considerar que o ser humano é um organismo com caraterísticas distintas das do Reino Animal, Aires (1906b) revelou conceções antropocêntricas ao afirmar, no prólogo do volume 2, que é o termo lógico e final da escala animal: "A descrição de cada aparelho [...] aparece no homem como o termo lógico e final duma série de disposições de fim comum, mas de complexidade gradualmente crescente à medida que se vai subindo na escala animal". (p. 5)

É nesse enquadramento, caraterizado pelo desenvolvimento dos vários sistemas biológicos se desenrolar numa direção de aperfeiçoamento que Aires (1906b) iniciou o estudo das raças humanas no capítulo intitulado "Noções de antropologia" do volume 2. Esse capítulo extravasou as deliberações programáticas, pois o autor começou por uma secção introdutória destinada à apresentação de algumas noções básicas de antropologia e à definição sucinta dos principais carateres antropológicos, como o ângulo facial, o índice cefálico, o índice nasal e o índice orbitário.

Essas medições de craniometria tiveram um forte desenvolvimento no século 19, altura em que foram fundamentadas por um forte volume de dados (Gould, 2004). Essa análise dos seres humanos conduziu a que fossem, em consequência, hierarquizados numa escala quantitativa ao atribuir à inteligência um valor numérico "capaz de classificar 
todos os indivíduos numa escala linear, de acordo com o valor mental intrínseco e inalterável de cada indivíduo" (Gould, 2004, p. 20).

A descrição propriamente dita das raças humanas e dos seus carateres inicia-se na lição 193. Nessa secção, Aires (1906b) cogitou sobre a definição das raças humanas, alertando que ao contrário das restantes espécies do Reino Animal, a sua delimitação não é simples:

Em Zoologia existem realmente os animais que formam as raças, as espécies, os géneros, etc., e feita a classificação, o lugar de qualquer indivíduo determina-se por comparação com os já classificados. Pelo contrário, em antropologia, os grupos naturais não existem caracterizados no seu conjunto, não estão por assim dizer personificados. (p. 166)

De igual forma, Júnior (1859) salientou que existe uma grande dificuldade na categorização das raças humanas devido a complicações na distinção entre os seus carateres. Inclusivamente, interrogou-se se "conhecer as funções da vida humana com respeito à raça caucásica, não será conhecê-las com respeito às outras raças mongólica, etíope, polinésia, americana, etc.?" (p. 151). Apesar dessas dúvidas, não hesitou em usar uma tipologia que dividiu as raças humanas em sete grupos, embora, segundo as suas palavras, existissem autores que apenas consideravam quatro raças: a branca ou caucásica; a amarela ou mongólica; a negra ou africana e a vermelha ou americana.

De facto, a classificação das raças humanas revelou-se um processo complexo, o que levou Martins (1881) a concluir que "é difícil classificar as raças humanas a não ser por um processo descritivo, isto é, segundo os seus carateres atuais" (p. 1). Acompanhando essa opinião, Aires (1906b) acrescentou que essa dificuldade é acentuada pela mistura entre povos, cujos cruzamentos originam tipos intermediários ${ }^{10}$. Por outro lado, considerou que quando dois povos se misturam ocorre com frequência a assimilação da cultura de um pelo outro, pelo que, em consequência, "nenhuma população atual, nem mesmo as acantonadas em pequenas ilhas [...] representa grupos naturais" (1906b, p. 166).

Apesar dessas dificuldades, considerou que "é a estes grupos naturais da família humana que se dá o nome de raças", rematando que "a raça em antropologia é um tipo ideal, resultante da análise dos carateres das populações, principalmente dos carateres físicos" (1906b, p. 167), assente em valores médios. Não obstante essas limitações, apresentou uma classificação das raças humanas, neste caso a que Topinard usou no livro Élements d'antropologie générale, modificada posteriormente por Canestrini (figura 1).

\footnotetext{
${ }^{10}$ Segundo Gould (2004), alguns naturalistas, como Agassiz, tinham um enorme temor da miscigenação racial através de casamentos mistos, tendo mesmo chegado a considerar "a produção de mestiços como um pecado contra a natureza" (p. 88). Sendo assim, embora não defendesse o esclavagismo, considerou que deveria manter-se uma rígida separação social entre as raças. A rutura com esse pensamento demorou muito tempo, pois a humanidade fez um longo percurso até predominarem ideias como as de Ribeiro (1978): "Nada do que se escreveu sobre os perigos da mestiçagem para a pureza da raça branca (mas qual?) e sobre a degenerescência dos mestiços tem a menor base científica." (p. 23).
} 


\section{Figura 1}

Classificação das raças humanas. ${ }^{11}$

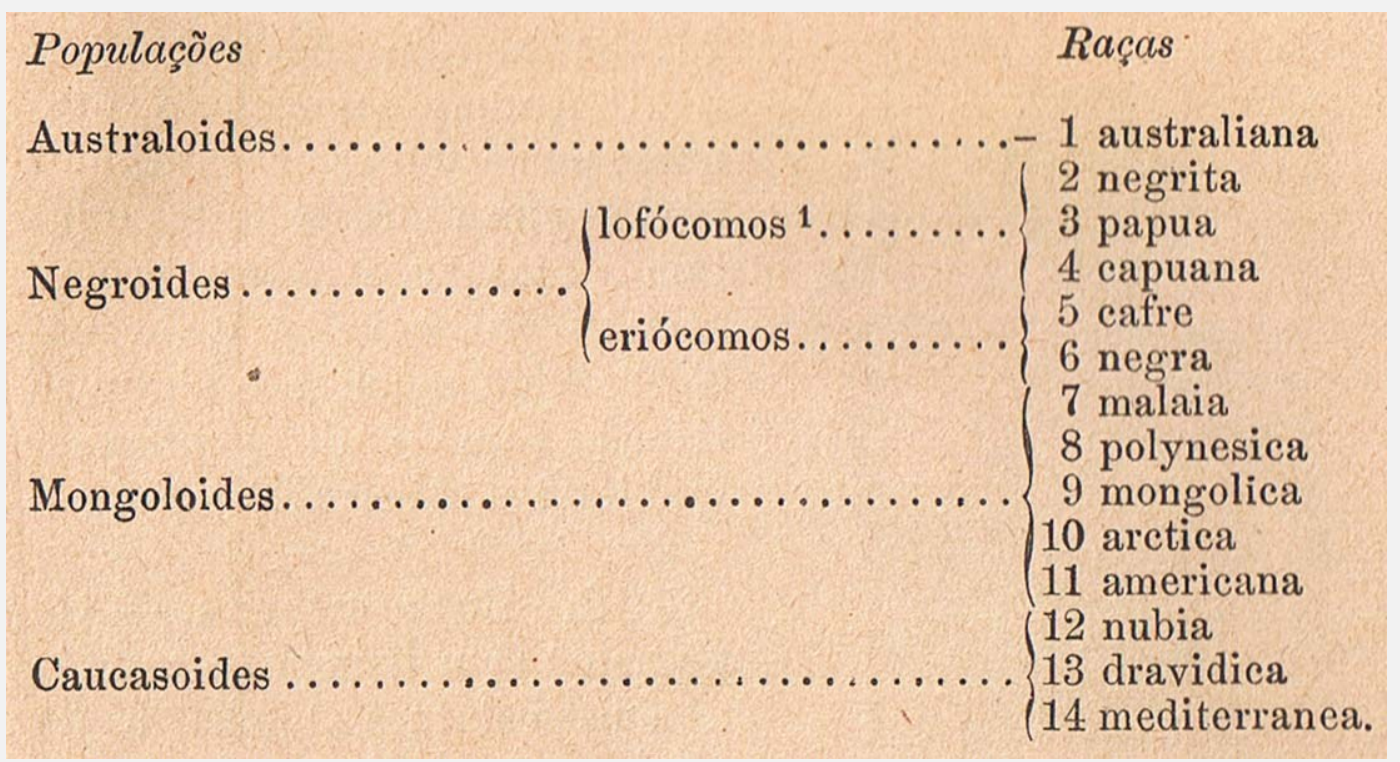

A classificação apresentada assemelha-se à defendida pelo naturalista Agassiz, apologista das raças humanas não serem uma espécie única ${ }^{12}$, mas o resultado de vários centros de criação humana, divididos em nove reinos: 1. Polinésio; 2. Australiano; 3. Malaio ou Índio; 4. Hotentote; 5. Africano; 6. Europeu. 7. Mongólico ou Asiático; 8, Americano; 9. Ártico (Martins, 1881).

O último programa analisado, datado de $1919^{13}$, suprimiu o estudo da caracterização das raças humanas. Essa eliminação não surpreende porque foi publicado durante a $1{ }^{a}$ República. Como um dos ideais republicanos é a igualdade entre todos os homens, a apresentação de uma secção programática destinada à catalogação dos seres humanos em raças não estaria de acordo com esse modelo ideológico. $\mathrm{Na}$ verdade, essa eliminação programática foi muito mais célere do que a observada, por exemplo, nos manuais de Ciências Naturais da Argentina, nos quais o conceito de raça só desapareceu após a década de 50 do século 20 , evidenciando a inversão do papel legitimador de certas práticas sociais racistas conferido aos manuais de Ciências Naturais (Gvirtz, Valerani e Cornejo, 2005).

Aliás, em alguns desses manuais existiram tendências contraditórias porque sustentaram o criacionismo, advogando a imutabilidade das espécies, ao mesmo tempo que afirmavam que a espécie humana apresenta variações (Gvirtz, Valerani e Cornejo, 2005). Essa discordância não se identificou nos manuais redigidos por Aires (1906b)

\footnotetext{
${ }^{11}$ Os lofócomos são indivíduos portadores de cabelos lanudos curtos e de espirais apertadas; os eriócomos são indivíduos que apresentam cabelos lanudos compridos e de espirais apertadas.

12 De acordo com Gould (2004), Agassiz converteu-se à teoria de que as raças humanas constituíam espécies distintas após os primeiros contactos com os negros americanos.

13 PORTUGAL. Decreto n. 6.132, de 26 de setembro de 1919. Diário do Governo, I Série, n. 196, de 26 de setembro de 1919, pp. 2056-2057.
} 
porque assentavam na teoria evolucionista (Cavadas, 2009). Provavelmente, devido às suas ideias evolucionistas, não separou a raça humana do táxon dos Primatas.

Análise comparativa das raças humanas nos manuais

Como Aires (1906b) foi o único autor de manuais a apresentar critérios de classificação das diferentes populações humanas em raças, no quadro seguinte apresentam-se as diferentes raças mencionadas e descritas nos manuais analisados, seguindo não uma tipologia contemporânea, mas a apresentada por esse autor (quadro 3).

\section{Quadro 3}

Raças caraterizadas nos manuais.

\begin{tabular}{|c|c|c|c|c|}
\hline \multicolumn{2}{|c|}{ Populações } & \multicolumn{3}{|c|}{ Manuais escolares de Zoologia } \\
\hline & & Júnior (1859) & Lemos (1890) & Aires (1906b) \\
\hline \multicolumn{2}{|c|}{ Australóides } & Raça australiana & -- & Raça australiana \\
\hline \multirow{2}{*}{ 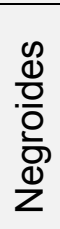 } & Lofócomos & Raça negra oceânica & -- & $\begin{array}{l}\text { Raça negrita } \\
\text { Raça papua } \\
\text { Raça capuana }\end{array}$ \\
\hline & Eriócomos & Raça negra & Raça etíope & $\begin{array}{l}\text { Raça cafre } \\
\text { Raça negra }\end{array}$ \\
\hline \multicolumn{2}{|c|}{ Mongolóides } & $\begin{array}{l}\text { Raça polinésica } \\
\text { Raça mongólica } \\
\text { Raça americana }\end{array}$ & $\begin{array}{l}\text { Raça malaia } \\
\text { Raça mongólica } \\
\text { Raça americana }\end{array}$ & $\begin{array}{l}\text { Raça malaia } \\
\text { Raça polinésica } \\
\text { Raça mongólica } \\
\text { Raça ártica } \\
\text { Raça americana }\end{array}$ \\
\hline \multicolumn{2}{|c|}{ Caucasóides } & Raça caucásica & Raça branca & $\begin{array}{l}\text { Raça núbia } \\
\text { Raça dravídica } \\
\text { Raça mediterrânea }\end{array}$ \\
\hline & Total & 7 & 5 & 14 \\
\hline
\end{tabular}

O próximo quadro (quadro 4) mostra os carateres antropológicos que cada um dos autores usou para descrever as raças anteriores, organizados em oito categorias. 
Quadro 4

Carateres antropológicos utilizados pelos autores dos manuais para descrever as raças humanas.

\begin{tabular}{|l|c|c|c|}
\hline \multirow{2}{*}{ Carateres antropológicos } & \multicolumn{3}{|c|}{ Manuais escolares } \\
\cline { 2 - 4 } & Júnior (1859) & Lemos (1890) & Aires (1906b) \\
\hline 1. Boca, dentes e lábios & $\sqrt{ }$ & $\sqrt{ }$ & $\sqrt{ }$ \\
\hline 2. Cabelo, barba e pêlos & $\sqrt{ }$ & $\sqrt{ }$ \\
\hline 3. Crânio, face e fronte & $\sqrt{ }$ & $\sqrt{ }$ \\
\hline 4. Maxilas e mento ${ }^{14}$ & $\sqrt{ }$ & $\sqrt{ }$ & $\sqrt{ }$ \\
\hline 5. Nariz & $\sqrt{ }$ & $\sqrt{ }$ & $\sqrt{ }$ \\
\hline 6. Olhos & $\sqrt{ }$ & $\sqrt{ }$ \\
\hline 7. Pele & $\sqrt{ }$ & 5 & 8 \\
\hline 8. Proporções corporais & $\sqrt{ }$ & & \\
\hline Total de categorias & 8 & & \\
\hline
\end{tabular}

Através da análise do quadro pode-se constatar que carateres como a boca, dentes e lábios; crânio, face e fronte; nariz; olhos e pele foram descritos por todos os autores. A descrição do cabelo, barba e pêlos, da maxila e mento e das proporções corporais foi considerada por Júnior (1859) e Aires (1906b) e negligenciada por Lemos (1890). Aires (1906b) aprofundou a descrição do crânio introduzindo variáveis como o índice cefálico e a capacidade craniana. No capítulo seguinte apresenta-se uma análise comparativa das raças mais focadas pelos autores em cada uma das populações anteriores.

\section{Populações australóides}

Os membros da raça australiana foram descritos apenas por Júnior (1959) e Aires (1906b). Foi notório que Aires (1906b) teceu considerações depreciativas sobre essa raça, nomeadamente sobre o odor da pele ao afirmar que "exala um cheiro desagradável e caraterístico" (p. 170), embora também tenha referido que os seus representantes pintam-se, tatuam-se e "tratam com esmero do cabelo e barba" (p. 170). Contudo, a consideração mais pejorativa foi sobre as suas capacidades intelectuais que classificou como "muito limitadas", em virtude da capacidade craniana ser pouco superior a $1.200 \mathrm{~cm}^{3}$, expressando as ideias de hierarquização das raças humanas através do tamanho médio do cérebro (Gould, 2004).

Na mesma linha de pensamento, Lemos (1890), embora não tenha caraterizado diretamente essa raça, teceu um comentário depreciativo sobre uma mulher australiana. Aquando da exposição das funções do cérebro, relacionou a inteligência com o tamanho dos hemisférios cerebrais e o seu número de circunvoluções, estabelecendo uma relação proporcional entre esses fatores e concluindo que o peso normal do cérebro é de $1.250 \mathrm{~g}$. Como exemplos de homens de grande inteligência, referiu Dupuytrein, Schiller e Cuvier,

\footnotetext{
${ }^{14} \mathrm{O}$ mento é a zona do rosto correspondente à parte anterior da mandíbula inferior, comummente conhecida por queixo.
} 
cujos cérebros pesavam, respetivamente, 1.436, 1.750 e $1.820 \mathrm{~g}$ e, comparativamente, afirmou que "pelo contrário o de uma mulher australiana de inteligência pouco desenvolvida pesava 907" (p. 113) ${ }^{15}$.

Como se pode constatar, por esta afirmação, a relação que pretende estabelecer entre o peso do cérebro e a inteligência é desfavorável ao género feminino porque quando essa proporção foi no sentido positivo foram indicados ilustres representantes do género masculino, e, quando foi desvantajosa, indicou-se um elemento do género oposto e de uma raça supostamente inferior. Note-se, assim, que, na consideração anterior, Lemos (1890) vinculou concomitantemente estereótipos de género e raciais ao utilizar como exemplo depreciativo uma mulher de raça distinta da caucasiana.

\section{Populações negroides}

As raças negra oceânica (Júnior, 1859), negrita, capuana e papua (Aires, 1906b) foram descritas resumidamente. Destaca-se a descrição dos capuanos, pois Aires (1906b) mencionou que, devido à ação dos missionários, "atualmente os papuas não são antropófagos" (p. 171) e que a capacidade craniana era de $1.450 \mathrm{~cm}^{3}$ no homem e 1.350 $\mathrm{cm}^{3}$ na mulher, desvalorizando este género, tal como Lemos (1890) fez quando teceu ilações sobre a mulher australiana.

Acerca das populações negroides, a raça a que os autores deram mais atenção foi a negra. Júnior (1859) indicou que se dividia nas sub-raças etiópica, cafre, nubiana, abissiniana e hotentótica ${ }^{16}$. Aires $(1906 \mathrm{~b})$ acrescentou a descrição de uma dessas subraças, a cafre. Por seu lado, Lemos (1890) não descreveu diretamente a raça negra, mas uma sub-raça, a etíope. O quadro seguinte resume os carateres antropológicos usados pelos autores para as descreverem.

\section{Quadro 6}

Carateres antropológicos da raça negra e sub-raças associadas.

\begin{tabular}{|l|c|c|c|c|}
\hline \multirow{2}{*}{ Carateres } & Júnior (1859) & Lemos (1890) & \multicolumn{2}{|c|}{ Aires (1906b) } \\
\cline { 2 - 5 } & Raça negra & Raça etíope & Raça negra & Raça cafre \\
\hline llustração & & & & \\
\hline $\begin{array}{l}\text { Boca, } \\
\text { dentes e } \\
\text { lábios }\end{array}$ & Lábios grossos. & Lábios grossos. & $\begin{array}{l}\text { Boca rasgada; } \\
\text { dentes muito alvos e } \\
\text { oblíquos, em ambas } \\
\text { as maxilas; lábios } \\
\text { grossos. }\end{array}$ & Cábios grossos. \\
\hline
\end{tabular}

${ }^{15}$ Curiosamente, Morton atribuiu à raça australiana uma capacidade craniana média de 75 polegadas cúbicas, a mais baixa de todas as raças e inferior em 17 polegadas cúbica à média da capacidade craniana da família teutónica do grupo caucasiano moderno (Gould, 2004, p. 96).

16 Sobre o povo hottentote, Martins (1881) mencionou que "como nunca nos estabelecemos no Cabo, foi aos holandeses que coube o dever de os expulsar dessa zona adequada para a vida de uma raça superior" (p. 91), espelhando convicções sobre o determinismo biológico. 


\begin{tabular}{|c|c|c|c|c|}
\hline $\begin{array}{l}\text { Cabelo, } \\
\text { barba e } \\
\text { pelos }\end{array}$ & $\begin{array}{l}\text { Cabelo crespo e } \\
\text { encarapinhado; } \\
\text { pêlos raros. }\end{array}$ & Lanoso e crespo. & $\begin{array}{l}\text { Cabelo negro e } \\
\text { lanudo; barba pouco } \\
\text { abundante e tardia; } \\
\text { pouco peludos. }\end{array}$ & $\begin{array}{l}\text { Cabelo lanudo e não } \\
\text { disposto em madeixas; } \\
\text { pouca barba. }\end{array}$ \\
\hline $\begin{array}{l}\text { Crânio, } \\
\text { face e } \\
\text { fronte }\end{array}$ & $\begin{array}{l}\text { Testa estreita e } \\
\text { comprida nas } \\
\text { fontes; ângulo } \\
\text { facial de } 60 \text { a } \\
70^{\circ} \text {. }\end{array}$ & $\begin{array}{l}\text { Crânio estreito e } \\
\text { alongado de diante } \\
\text { para traz; Fronte } \\
\text { estreita. }\end{array}$ & $\begin{array}{l}\text { Dolicocéfalos; } \\
\text { capacidade craniana } \\
\text { inferior a } 1400 \mathrm{~cm}^{3 . .} \\
\text { Face comprida e } \\
\text { estreita; fronte } \\
\text { estreita; arcadas } \\
\text { supraciliares pouco } \\
\text { acentuadas; fontes } \\
\text { escavadas. }\end{array}$ & $\begin{array}{l}\text { Dolicocéfalos (72 em } \\
\text { média); capacidade } \\
\text { craniana de } 1450 \mathrm{~cm}^{3} \text {. } \\
\text { Média do ângulo facial: } \\
68,21^{\circ} \text {; fronte bem } \\
\text { arqueada; órbitas } \\
\text { separadas; região } \\
\text { occipital desenvolvida. }\end{array}$ \\
\hline $\begin{array}{l}\text { Maxilas e } \\
\text { mento }\end{array}$ & $\begin{array}{l}\text { Maxilas } \\
\text { salientes. }\end{array}$ & $\begin{array}{l}\text { Maxilas muito } \\
\text { salientes. }\end{array}$ & Mento curto. & $\begin{array}{l}\text { Mandíbula com } \\
\text { prognatismo acentuado. }\end{array}$ \\
\hline Nariz & $\begin{array}{l}\text { Nariz curto e } \\
\text { achatado; } \\
\text { membranas } \\
\text { mucosas roxas. }\end{array}$ & Nariz chato. & Nariz largo e chato. & Nariz alto. \\
\hline Olhos & -- & -- & $\begin{array}{l}\text { Olhos negros, } \\
\text { horizontais e com as } \\
\text { pálpebras caídas. }\end{array}$ & \\
\hline Pele & -- & Negra. & $\begin{array}{l}\text { Aveludada e luzidia, } \\
\text { variando do preto de } \\
\text { azeviche até ao } \\
\text { avermelhado, azulado } \\
\text { ou escuro. }\end{array}$ & Escura. \\
\hline $\begin{array}{l}\text { Proporções } \\
\text { corporais }\end{array}$ & -- & -- & $\begin{array}{l}\text { Estatura muito } \\
\text { elevada e corpo } \\
\text { delgado; alguns são } \\
\text { baixos; membros } \\
\text { superiores } \\
\text { compridos; barriga } \\
\text { das pernas pouco } \\
\text { desenvolvida. }\end{array}$ & $\begin{array}{l}\text { Estatura elevada, } \\
1,70 \mathrm{~m} \text {, em média. }\end{array}$ \\
\hline
\end{tabular}

Aires (1906b) teceu considerações de ordem moral sobre essa raça ao referir que "os seus traços morais são a leviandade, a indolência e a imprevidência. Muito dados à música, dança e folguedos." (p. 172). Ainda aludiu, também, ao facto das tribos dos negros do Congo e dos herreros, da raça cafre, serem muito belicosas. Acerca da indolência dos negros, Gould (2004) afirmou que foi uma ideia partilhada inclusivamente por grandes naturalistas, como Lineu, Cuvier e Lyell. Martins (1881) também advogou que os "dotes psicológicos" ( $p . \mathrm{XL}$ ) das raças poderiam promover, ou impedir, o seu percurso em direção ao progresso e considerou-os essenciais para o processo de classificação antropológica: "os carateres morais dos povos são de um valor inestimável em etnologia; sem dúvida são essenciais para determinar, conjuntamente com outros, as descendências ou afinidades étnicas" (p. 14).

Este tipo de ilações reforçava a ideia de que os negros eram inferiores e que a sua condição biológica justificava a escravatura e a colonização (Gould, 2004) ${ }^{17}$. De facto, foram comummente apresentadas em manuais escolares de diversos países como, por

\footnotetext{
${ }^{17}$ Apesar da escravatura ter vindo a ser abolida gradualmente nos territórios portugueses, foi somente em 1869 que se proclamou a abolição da escravatura em todo o Império Português, até à sua suposta erradicação definitiva em 1878.
} 
exemplo, num manual escolar publicado nos Estados Unidos em 1938: "Ethiopian savages represent low human types; some are cannibals; homes, weapons, and implements most primitive" (Skoog, 2005, p. 401).

Esse não foi um caso único, pois Skoog (2005) concluiu que a diferenciação racial dos seres humanos foi enfatizada com profundidade considerável em outros manuais escolares publicados entre 1930 e 1939. As considerações morais anteriores também foram identificadas em manuais da Argentina. A esse respeito, atente-se no paralelismo com a descrição dos carateres da raça negra realizada por Aires (1906b) com os tecidos por Junquera Muné, autor de manuais de Ciências Naturais, numa obra publicado em 1930:

Os negros manifestam poucas capacidades intelectuais e sociais. Nunca foram capazes de viver em grandes organizações. São preguiçosos e débeis de carácter. Por essas razões, vivem inteiramente dominados pelos brancos [...] A raça branca é a única que possui verdadeira capacidade de socialização [...] é a que mais se aperfeiçoou e a que transmitiu a sua cultura para as gerações e raças de todo o mundo, colonizando e ensinando como viver. É a raça da civilização. (apud Gvirtz, Valerani e Cornejo, 2005, p. 475)

De facto, essas considerações pareciam ser necessárias para uma tese evolucionista sobre a família, que se iniciaria na promiscuidade das raças primitivas e terminaria no tipo familiar característico das sociedades civilizadas ocidentais, o casamento monogâmico (Leal, 2006).

\section{Populações mongoloides}

No enquadramento das populações mongoloides, as raças polinésica e malaia também foram sucintamente descritas pelos autores. Aires (1906b), dissertando sobre a raça malaia, considerou que os géneros "são muito semelhantes" (p. 173). Note-se que essa semelhança é subjetiva, pois os diferentes géneros apenas se assemelhariam a olhos ocidentais, não treinados e não habituados a distinguir os carateres antropológicos que diferem os dois géneros.

Quanto à raça polinésica, Aires (1906b) especificou que os seus membros possuem um caracter típico, a "obesidade frequente" (p. 174). Esta raça também foi dada como exemplo por Martins (1881) do processo de decadência das civilizações e de degenerescência das raças, pois, segundo afirmou: "quando os europeus os descobriram acharam-nos num estado evidente de regressão à vida selvagem, porque só num estado superior poderiam ter efetuado as suas migrações marítimas" (p. 54), vinculando a ideia de uma determinada progressão racial.

A raça mongólica foi das mais profusamente descritas pelos três autores, destacando-se uma consideração depreciativa de Júnior (1859) que considerou os seus membros corporais mal desenhados.

Quanto à raça ártica, o único autor a abordá-la foi Aires (1906b), que a considerou como uma variedade da mongólica. Na mesma linha de pensamento, Martins (1881) referiu: "exagere-se a fisionomia mongólica, deprima-se a estatura, amesquinhe-se a espécie, entorpeça-se a inteligência, tudo isto o frio dessa regiões boreais é capaz de 
produzir, e ter-se-á um esquimó ou um groenlandês" (p. 145), relacionando o clima com a degenerescência da raça ártica.

Todos os autores descreveram a raça americana, embora com diferentes graus de desenvolvimento.

\section{Quadro 6}

Carateres antropológicos da raça americana.

\begin{tabular}{|c|c|c|c|}
\hline \multirow[t]{2}{*}{ Carateres } & \multicolumn{3}{|c|}{ Raça americana } \\
\hline & Júnior (1859) & Lemos (1890) & Aires(1906) \\
\hline Ilustração & -- & Americano & Americano \\
\hline $\begin{array}{l}\text { Boca, dentes e } \\
\text { lábios }\end{array}$ & -- & -- & $\begin{array}{l}\text { Boca grande; dentes } \\
\text { verticais. }\end{array}$ \\
\hline $\begin{array}{l}\text { Cabelo, barba e } \\
\text { pelos }\end{array}$ & Cabelo liso; barba rara. & $\begin{array}{l}\text { Cabelo liso, áspero e } \\
\text { negro. }\end{array}$ & $\begin{array}{l}\text { Cabelo comprido, negro, liso } \\
\text { e rijo como crinas; barba } \\
\text { rara, negra, tardia, existindo } \\
\text { somente no bigode e no } \\
\text { mento; corpo quase glabro. }\end{array}$ \\
\hline $\begin{array}{l}\text { Crânio, face e } \\
\text { fronte }\end{array}$ & Testa pouco elevada. & $\begin{array}{l}\text { Crânio estreito e alongado. } \\
\text { Face larga; maças do rosto } \\
\text { proeminentes. }\end{array}$ & $\begin{array}{l}\text { Índice cefálico: Geralmente } \\
\text { dolicocéfalos. } \\
\text { Face larga; fronte larga, mas } \\
\text { baixa e fugidia; arcadas } \\
\text { supraciliares bem } \\
\text { desenvolvidas. }\end{array}$ \\
\hline Maxilas e mento & -- & Maxilas pouco salientes. & Mandíbula prognáta. \\
\hline Nariz & $\begin{array}{l}\text { Nariz arqueado, sem ser } \\
\text { aquilino, fossas nasais } \\
\text { muito desenvolvidas. }\end{array}$ & Nariz comprido. & $\begin{array}{l}\text { Nariz saliente e às vezes } \\
\text { aquilino, com narinas largas. }\end{array}$ \\
\hline Olhos & Olhos horizontais. & Olhos encovados. & $\begin{array}{l}\text { Olhos pequenos, encovados } \\
\text { e frequentemente oblíquos. }\end{array}$ \\
\hline Pele & $\begin{array}{l}\text { Amarela em geral; } \\
\text { vermelha em algumas } \\
\text { raças. }\end{array}$ & Vermelha acobreada. & $\begin{array}{l}\text { Escuro-olivácea, misturada } \\
\text { de branco ou avermelhado e } \\
\text { às vezes cor-de-canela. }\end{array}$ \\
\hline $\begin{array}{l}\text { Proporções } \\
\text { corporais }\end{array}$ & -- & -- & $\begin{array}{l}\text { Estatura superior à média; } \\
\text { muito elevada nos patagões, } \\
\text { mas por vezes baixa, como } \\
\text { nos foguianos. }\end{array}$ \\
\hline
\end{tabular}

Cogitando sobre a raça americana, Aires (1906b) indicou que é pouco homogénea, pois, devido à grande extensão do continente americano, os indígenas da América setentrional e central, comummente conhecidos por peles vermelhas, são muito diferentes dos da América do Sul. Vaticinou, também, a sua extinção, ao considerar que "tende a desaparecer diante dos imigrantes de outras raças" (p. 177), apesar de, no contexto da 
dificuldade em estabelecer objetivamente raças humanas, ter acentuado o discurso de mistura racial, em vez de supressão de uma raça por outra:

Não é preciso recorrer à linguística à arqueologia pré-histórica, etc., para nos convencermos de que, se numa dada época os grupos naturais do homem viveram separados uns dos outros, com o decorrer do tempo cruzaram-se e fundiram-se, dando lugar a tipos intermediários mais ou menos diferentes. (p. 166)

Todavia, essa perspetiva de miscigenação pacífica não foi uniforme, pois na continuação da afirmação anterior também considerou que pode ser violenta: "a história mostra, com efeito, como têm sido frequentes as misturas de povos, quer por imigrações pacíficas, quer por invasões e armadas" (p. 166), tal como vaticinou para a raça americana. Esse desaparecimento, obviamente que para além de resultar de cruzamentos inter-raciais relativamente pacíficos, também foi promovido pelo desaparecimento violento de grandes números de indivíduos da raça americana autóctone provocado pelos imigrantes, nomeadamente os provenientes do continente europeu.

Foi nesse sentido que Martins (1881) referiu que "não chegam já a trezentos mil, esses índios. É uma gente que se extingue, um tipo humano que desaparece" (p. 146), vaticinando que iriam desaparecer os traços dessa raça indígena.

\section{Populações caucasóides}

Integrados nas populações caucasóides, os núbios e os membros da raça dravídica foram caraterizados apenas por Aires (1906b), embora de forma lacunar. Pelo contrário, a raça branca foi descrita por todos os autores.

\section{Quadro 7}

Carateres antropológicos da raça branca.

\begin{tabular}{|c|c|c|c|}
\hline \multirow[t]{2}{*}{ Carateres } & \multicolumn{3}{|c|}{ Raça branca } \\
\hline & Júnior (1859) & Lemos (1890) & Aires (1906b) \\
\hline Ilustração & -- & Raça branca. & -- \\
\hline $\begin{array}{l}\text { Boca, dentes e } \\
\text { lábios }\end{array}$ & $\begin{array}{l}\text { Boca pequena; incisivos } \\
\text { verticais, formando um } \\
\text { ângulo de } 80 \text { a } 90^{\circ} \text {; lábios } \\
\text { delgados. }\end{array}$ & Dentes verticais. & $\begin{array}{l}\text { Lábios finos e rosados; } \\
\text { dentes pequenos e } \\
\text { verticais. }\end{array}$ \\
\hline $\begin{array}{l}\text { Cabelo, barba } \\
\text { e pelos }\end{array}$ & $\begin{array}{l}\text { Cabelo preto, às vezes } \\
\text { castanho, mas sempre } \\
\text { liso, longo e brilhante; } \\
\text { barba espessa. }\end{array}$ & -- & $\begin{array}{l}\text { Cabelo e barba } \\
\text { compridos, às vezes } \\
\text { crespos ou lanudos, } \\
\text { negros, castanhos ou } \\
\text { louros e raramente }\end{array}$ \\
\hline
\end{tabular}




\begin{tabular}{|l|l|l|l|}
\hline & & & $\begin{array}{l}\text { arruivados; corpo mais ou } \\
\text { menos peludo, } \\
\text { principalmente no } \\
\text { homem. }\end{array}$ \\
\hline $\begin{array}{l}\text { Crânio, face e } \\
\text { fronte }\end{array}$ & $\begin{array}{l}\text { Testa elevada; rosto oval; } \\
\text { maçãs do rosto pouco } \\
\text { salientes. }\end{array}$ & $\begin{array}{l}\text { Curto e arredondado. Fronte } \\
\text { direita e elevada } \\
\text { verticalmente. }\end{array}$ & $\begin{array}{l}\text { Capacidade craniana: } \\
1500 \mathrm{~cm}^{3} . \\
\text { Face oblonga; ângulo } \\
\text { facial muito elevado; } \\
\text { fronte elevada. }\end{array}$ \\
\hline $\begin{array}{l}\text { Maxilas e } \\
\text { mento }\end{array}$ & Mento saliente. & Mento desenvolvido. \\
\hline Nariz & Longo. & Estreito. & $\begin{array}{l}\text { Nariz afilado e às vezes } \\
\text { aquilino. }\end{array}$ \\
\hline Olhos & -- & -- & $\begin{array}{l}\text { Olhos negros, escuros, } \\
\text { azuis, castanhos ou com } \\
\text { cores intermédias; fenda } \\
\text { palpebral horizontal. }\end{array}$ \\
\hline Pele & $\begin{array}{l}\text { Fina, branca ou cor-de- } \\
\text { rosa. }\end{array}$ & Branca. & $\begin{array}{l}\text { Branca-rosada e às vezes } \\
\text { morena. }\end{array}$ \\
\hline $\begin{array}{l}\text { Proporções } \\
\text { corporais }\end{array}$ & Pés e mãos regulares. & -- & $\begin{array}{l}\text { Estatura variável, } \\
\text { geralmente não muito } \\
\text { baixa. }\end{array}$ \\
\hline
\end{tabular}

O texto correspondente à descrição da raça branca mostrou um evidente determinismo biológico em seu favor. Por exemplo, Júnior (1859) atribuiu mais qualidades à raça caucasiana do que às restantes, distinguindo-a pela "formosura, e beleza de formas [e um] talhe de corpo elegante" (p. 155). Na mesma linha de pensamento, Aires (1906b) considerou que a raça mediterrânea é "a mais bela e elevada sob o ponto de vista da cultura e desenvolvimento do espírito" (p. 178). A valorização estética da raça branca, em comparação com as outras raças, foi uma ideia bastante comum na época (Gould, 2004). Por outro lado, a raça branca era também vista como civilizadora e dominadora, como atestam as seguintes palavras de Martins (1881):

Na história, a nossa arena é o mundo; e no concurso das raças dos seus habitantes humanos, o domínio coube à dos indo-europeus que adiante de todos chegaram a conquistar para si os elementos de uma ação que reage sobre todos os outros povos paros avassalar, ou para os exterminar. ( $p$. XLII)

A supremacia dessa raça também foi constatada por Skoog (2005) nos manuais elaborados pelos autores Moon e Mann: "the highest modern civilization has been developed in countries where Nordic, Alpine, and Mediterranean races predominate" ( $p$. 402). De facto, os manuais publicados entre 1930 e 1940 nos Estados Unidos parecem ter enfatizado a eugenia, valorizando consideravelmente a raça caucasiana em detrimento das outras. Esses pressupostos levam-nos a supor que Aires (1906b) atribuiu intencionalmente a essa raça a maior capacidade craniana $\left(1.500 \mathrm{~cm}^{3}\right)$.

\section{Os portugueses}

Aires (1906b) ainda dedicou ainda algumas linhas ao enquadramento dos portugueses no quadro racial. Indicou que pertencem à sub-raça dos indo-europeus e mencionou que entre os portugueses é possível distinguir diferentes grupos de acordo 
com o carácter selecionado. Por exemplo, referiu que vivem em Portugal tanto o tipo dolicocéfalo como o braquicéfalo ou tanto o tipo louro como o moreno.

Importa abordar com mais atenção à multiplicidade de características dos portugueses, a qual era conhecida na Europa e alvo de críticas e até de algum escárnio por parte de alguns países estrangeiros, como constatou Pereira (2001): "a imagem de fealdade do português que corria no estrangeiro ofendia o narcisismo ariocêntrico da raça" (p. 485). Contestando essa visão negativista da raça portuguesa, mencionou que Zeferino Cândido, no artigo Portugal no extrangeiro, publicado no jornal O Século, negava que "o português fosse uma 'raça de cor' como se pretendia na conceituada Revue Scientifique" (p. 486). A acompanhar as críticas de Zeferino Cândido estava Amado, que relativamente à cor de pele dos portugueses afirmou "é raro que um português não mostre nas suas características a prova mais ou menos evidente do cruzamento de um tipo loiro com um tipo moreno" (apud Pereira, 2001, p. 486).

Todavia, as críticas não acabaram por aí, pois numa obra elaborada por especialistas estrangeiros e da chancela da Larousse, intitulada Le Portugal, datada de 1900, Pereira (2001) referiu que manteve a ideia de que a raça portuguesa acusava "uma acentuada marca física e mental de sangue negro" (p. 486). Segundo a mesma autora, essa afirmação foi muito contestada por Rocha Peixoto, para quem a arianidade física e mental do português não era questionável, embora se pudesse observar alguma influência semita. Essa influência conduziu a que Adolfo Coelho sugerisse, inclusivamente, uma regermanização da Península Ibérica, para reforçar os traços arianos dos povos peninsulares. Aliás, a preocupação com a decadência e regeneração nacional acabou por ter algum impacto na obra antropológica de Adolfo Coelho (Leal, 2006).

\section{Reflexões finais}

Este trabalho mostra que, nos manuais de Zoologia portugueses, o conceito de raça aplicada ao ser humano foi apresentado desde as primeiras obras e, pelo menos, até às publicadas no início do século 20. Os primeiros programas republicanos, publicados em 1919, abandonaram o estudo das raças humanas.

A ideia de que os seres humanos se poderiam hierarquizar numa escala quantitativa e qualitativa foi patente em alguns trechos dos manuais analisados. Por exemplo, a raça negra e a caucasiana foram descritas moralmente por Aires (1906b), que desvalorizou a primeira. O tamanho médio do cérebro foi outro fator que alguns autores (Lemos, 1890; Aires, 1906b) usaram para mostrar que a raça branca era superior às outras. Essas ilações sustentavam-se empiricamente nos quadros-resumo da capacidade craniana das diferentes raças elaborados por Morton (Gould, 2004). Esse tipo de juízos de ordem moral e intelectual provavelmente não foi inocente porque, na época, Portugal era um país colonizador e, talvez por acaso ou premeditação, nos manuais a raça negra e a branca foram caracterizadas moralmente, em sentidos opostos.

Esse tipo de comparações permite extrapolar que as crenças de Júnior (1859) e Aires (1906b) na gradação crescente dos organismos na escala animal também se aplicaria às raças humanas, pois suceder-se-iam numa complexidade contínua, física, moral e intelectual, que culminaria na raça branca. Essa ordenação também esteve patente no manual elaborado por Lemos (1890), pois primeiro descreveu a raça malaia, à qual se seguiu a americana, a etiópica, a mongólica e, por fim, a branca, transmitindo a 
ideia de que uma complexificação crescente das características raciais que culminaria na mais bela e perfeita, a caucasiana. Esta ilação é sustentada pelo facto de considerar que os mamíferos "constituem a classe mais adiantada em organização" (p. 245).

Portanto, se para este autor há uma gradação no Reino Animal, que culmina nos mamíferos, não será incorreto supor que a mesma se extrapolaria para a espécie mais preponderante desse reino, a humana, tal como Gould (2004) assinalou: "desde as amibas até Deus, tudo se ordena numa única sequência, que inclui, perto do seu ponto culminante, uma série hierárquica de raças e classes humanas" (p. 69). De facto, tanto na obra de Lemos (1890) como no manual de Aires (1906b), a raça branca foi a última a ser descrita, reforçando a ideia, a par do desenvolvimento dos restantes temas em que os seres vivos foram apresentados dos mais simples para os mais complexos, que é superior e mais desenvolvida do que as restantes raças.

Essa progressão parece reflectir a antropologia evolucionista que entendia as sociedades primitivas não como exemplos da diversidade cultural do género humano, mas como as primeiras manifestações de um processo de desenvolvimento cultural e social que culminaria na sociedade europeia do século 19 (Leal, 2006).

Constatou-se, ainda, que a apresentação dos carateres antropológicos do corpo não seguiu nenhuma ordem aparente. Salienta-se, também, a diferenciação iconográfica entre as três obras. No manual elaborado por Júnior (1859), a ausência de iconografia ilustrativa das diferentes raças dificultaria de sobremaneira ao leitor a comparação entre cada um dos carateres descritos. Em contrapartida, no manual de Lemos (1890), a apresentação de retratos de cada tipo racial auxiliaria, de certa forma, ao reconhecimento de alguns dos carateres descritos. Porém, é no manual de Aires (1906b) que é apresentada a iconografia de melhor qualidade pois, para além do rosto, algumas imagens ilustram indivíduos em corpo inteiro, na sua grande maioria do género masculino.

Em suma, nos manuais analisados foram evidentes as diferenças na tipologia racial usada, assim como nos carateres antropológicos utilizados pelos autores para descrever as raças humanas. De forma geral, o texto usado para descrever esses carateres foi objetivo. Contudo, também se aferiu, à luz da cultura contemporânea, alguns estereótipos raciais manifestos na valorização física, moral e intelectual da raça caucasiana em detrimento dos outros tipos raciais. Isso indicia que os autores eram apologistas do determinismo biológico resultante dos membros das distintas raças humanas possuírem culturas e um corpo diferentes.

\section{Referências}

AIRES, Bernardo. Lições de zoologia para a $1 .^{a}, 2^{a}$ e $3{ }^{a}$ classes dos lyceus. V. 1. Braga: Livraria Escolar Cruz \& C. ${ }^{\text {, }}$ 1906a.

AIRES, Bernardo. Lições de zoologia para a $4 .^{a}$ e $5 .^{a}$ classes dos lyceus. V. 2. Braga: Livraria Escolar Cruz \& C. a , 1906b.

CAVADAS, Bento. A evolução dos manuais escolares de Ciências Naturais do ensino secundário em Portugal (1836-2005). Salamanca: Universidad de Salamanca, 2008. 943f. Tese (Doutorado em Política e Fundamentos Educativos), Facultad de Educación, Universidade de Salamanca. 
CAVADAS, Bento. O darwinismo nos manuais escolares portugueses de zoologia (18591909), Cadernos de Investigação Aplicada, v. 3, 2009, p. 63-95.

BEATO, Carlos. Os liceus e as ciências (1836-1860): um estudo sobre o processo de criação das disciplinas de ciências físicas e naturais nos liceus portugueses. Lisboa: Universidade de Lisboa, 2012. 555f. Tese (doutorado em Educação). Instituto de Educação, Universidade de Lisboa.

BOGDAN, Robert; BIKLEN, Sari. Investigação qualitativa em educação: uma introdução à teoria e aos métodos. Porto: Porto, 1994.

CAETANO, Sílvia. Representações de género e de etnia: estudo realizado em manuais escolares de Educação Física do $3 .^{\circ}$ ciclo do Ensino Básico. Porto: Universidade do Porto, 2005. 161f. Tese (mestrado em Ciência do Desporto). Área de Especialização em Desporto de Crianças e Jovens, Faculdade de Ciências do Desporto e Educação Física da Universidade do Porto.

CHEVALLARD, Yves. La transposición didáctica: del saber sabio al saber ensinado. Buenos Aires: Aique, 1991.

CHOPPIN, Alain. Manuels scolaires: histoire et actualité. Paris: Hachette Éducation, 1992.

CORREIA, Anabela; RAMOS, Maria. Representações de género em manuais escolares. Língua Portuguesa e Matemática: 1. ${ }^{\circ}$ ciclo. Lisboa: CIDM, 2002.

FIALHO, Irene. Popular e popularizante nos manuais escolares do Estado Novo. Tese (mestrado em Literaturas Comparadas - Época Contemporânea). Lisboa: Universidade Nova de Lisboa, 1993. 313f. Faculdade de Ciências Sociais e Humanas, Universidade Nova de Lisboa.

GOULD, Stephen. A falsa medida do homem. Vila Nova de Famalicão: Quasi, 2004.

GVIRTZ, Silvina; VALERANI, Alejandra; CORNEJO, Jorge. Razaz, racismo y la politización de los contenidos en la historia de la escuela argentina (1854-1990). In: GUEREÑA, Jean-Louis; OSSENBACH, Gabriela; POZO, Maria del Mar (dirs.). Manuales escolares en España, Portugal y América Latina (siglos 19 y 20). Madrid: Uned, 2005, p. 471-484.

JÚNIOR, José. Lições de zoologia elementar. 1. a parte. Lisboa: Typographia de Castro \& Irmão, 1859.

JÚNIOR, José. Lições de zoologia elementar. 2. ${ }^{a}$ parte. Lisboa: Typographia de Castro \& Irmão, 1860.

LEAL, João. Antropologia em Portugal: mestres, percursos, tradições. Lisboa: Livros Horizonte, 2006.

LEMOS, Maximiano. Elementos de zoologia: $4 .^{\circ}$ e $5 .^{\circ}$ annos do curso de sciencias. Porto: Lemos e C. ${ }^{a}, 1890$.

MARTELO, Maria de Jesus. A escola e a construção da identidade das raparigas: o exemplo dos manuais escolares. Lisboa: CIDM, 1999.

MARTINS, J. P. As raças humanas e a civilização primitiva. Lisboa: Livraria Bertrand, 1881.

MORGADO, José. Manuais escolares: contributos para uma análise. Porto: Porto, 2004.

MUCZNIK, Esther. A religião nos manuais escolares. Lisboa: Comissão da Liberdade Religiosa, 2007. 
NUNES, Maria. Género e cidadania nas imagens de história: estudo exploratório de manuais escolares do $12 .^{\circ}$ ano e de software educativo. Lisboa: Universidade Aberta, 2004. 229f. Tese (mestrado em Comunicação Educacional Multimédia). Universidade Aberta.

PEREIRA, Ana. Darwin em Portugal: filosofia, história, engenharia social (1865-1914). Coimbra: Livraria Almedina, 2001.

PEREIRA, Paula. Modelados pelo discurso: uma análise crítica das representações de género em manuais escolares do $1 .^{\circ}$ ciclo. Lisboa: Universidade de Lisboa, 2003. $206 f$. Tese (mestrado em Linguística Aplicada). Faculdade de Letras da Universidade de Lisboa.

PINTO, Teresa. A avaliação dos manuais escolares numa perspectiva de género. ENCONTRO INTERNACIONAL SOBRE MANUAIS ESCOLARES, 1, 1999, Braga. Actas ... Braga: Instituto de Educação e Psicologia da Universidade do Minho, 1999, p. 387-395.

PORTUGAL. Decreto n. 6.132, de 26 de setembro de 1919. Diário do Governo, I Série, n. 196, de 26 de setembro de 1919.

PORTUGAL. Decreto n. 3, de 3 de novembro de 1905. Diário do Governo, n. 250, de 4 de novembro de 1905.

PORTUGAL. Decreto de 14 de setembro de 1895. Diário do Governo, n. 208, de 16 de setembro de 1895.

PORTUGAL. Edital (s.d.). Diário do Governo, n. 122, de 26 de maio de 1856.

PORTUGAL. Portaria de 10 de outubro de 1889. Diário do Governo, n. 245, de 29 de outubro de 1889.

PORTUGAL. Portaria de 20 de outubro de 1888. Diário do Governo, n. 252, de 3 de Novembro de 1888.

PORTUGAL. Portaria de 19 de novembro de 1886. Diário do Governo, n. 267, de 23 de novembro de 1886.

PORTUGAL. Portaria (s.d.). Diário do Governo, n. 241, de 21 de outubro de 1880.

PORTUGAL. Portaria de 5 de outubro de 1872. Diário do Governo, n. 231, de 12 de outubro de 1872.

PRATS, Joseph (coord.). As raças humanas. v. 1. Lisboa: Resomnia, 1988.

RIBEIRO, Orlando. A Terra e a variedade humana: as raças. Finisterra (Separata), v. 13, n. 25, 1979, p. 1-34.

ROCHA, Fernando. A representação da mulher e da condição feminina nos manuais escolares de português do ensino secundário. ENCONTRO INTERNACIONAL SOBRE MANUAIS ESCOLARES, 1, 1999, Braga. Actas ... Braga: Instituto de Educação e Psicologia da Universidade do Minho, 1999, p. 415-421.

ROSEMBERG, Fúlvia; BAZILLI, Chirley; SILVA, Paulo. Racismo em livros didáticos brasileiros e seu combate: uma revisão da literatura. Educação e Pesquisa, v. 29, n. 1, jan./jul., 2003, p. 125-146.

SCOTT, Eugenie. Evolution vs. creationism: an introduction. Berkeley: University of California Press, 2009.

SKOOG, Gerald. The coverage of human evolution in high school Biology textbooks in the 20th century and in current state science standards. Science \& Education, n. 14, 2005, p. 395-422. 
STELLING, Luiz. Raças humanas e raças biológicas em livros didáticos de Biologia de ensino médio. Niterói: UFF, 2007. 171f. Tese (doutorado em Educação). Programa de Pós-Graduação em Educação, Universidade Federal Fluminense.

BENTO FILIPE BARREIRAS PINTO CAVADAS é doutor em Política e Fundamentos Educativos pela Universidade de Salamanca e investigador integrado do Centro de Estudos e Intervenção em Educação e Formação da Universidade Lusófona de Humanidades e Tecnologias. É professor da Escola Superior de Educação de Santarém e coordenador do curso de licenciatura em Educação Básica.

Morada: Complexo Andaluz, Apartado 131, 2001-902 - Santarém - Portugal.

E-mail: bento.cavadas@ese.ipsantarem.pt.

Recebido em 2 de junho de 2012.

Aceito em 23 de outubro 2012. 